\title{
Queratocisto odontogênico: relato de caso
}

\author{
Odontogenic keratocystic: case report \\ Queratoquiste odontogénico: reporte de caso \\ Maylson Alves Nogueira BARROS \\ Vitor Bruno TESLENCO \\ Guilherme Nucci dos REIS \\ Herbert Cavalcanti de ABREU \\ Serviço de Cirurgia e Traumatologia Bucomaxilofacial da Associação Beneficente Santa Casa de Campo Grande, 79002.251 Campo Grande - MS, Brasil.
}

\section{Resumo}

O queratocisto compreende um cisto odontogenico que surge dos restos da lâmina dentaria associado a alterações genéticas no gene PTCH1, aumento expressão PCNA, Ki-67, extinção de vários genes supressores tumorais. Apresenta comportamento agressivo, invasivo, altamente redicivante e com potencial de malignização. Este relato de caso tem como objeto apresentar tratamento conservador de um queratocisto odontogenico. Paciente sexo feminino, leucoderma, 19 anos, encaminhada ao ambulatório do serviço Cirurgia e Traumatologia Bucomaxilofacial, com queixa de dormência do lábio inferior, associado dor em região mandibular direita. Foi diagnosticada com queratocisto odontogenico, onde foi submetida enucleação com piezocirurgia associado a cauterização química sob anestesia geral. O tratamento proposto foi efetivo até atual momento, a neoformação óssea é evidenciada, ausência de sinais clínicos e radiográficos de recidiva. Porém é necessário um acompanhamento a longo prazo para constatação da ausência de recidiva.

Descritores: Patologia Bucal; Cistos Ósseos; Cirurgiões Bucomaxilofaciais.

\section{Abstract}

The keratocyst comprises an odontogenic cyst arising from the remains of the dental lâmina associated with genetic alterations in the PTCH1 gene, increased PCNA expression, Ki-67, extinction of several tumor suppressor genes. It presents aggressive, invasive, highly redicidal and malignant potential. This case report aims to present conservative treatment of an odontogenic keratocyst. Female patient, leucoderma, 19 years old, referred to the outpatient clinic of Buccomaxillofacial Surgery and Traumatology, complaining of lower lip numbness, associated pain in the right mandibular region. She was diagnosed with odontogenic keratocyst, where she underwent enucleation with piezo surgery associated with chemical cauterization under general anesthesia. The proposed treatment was effective until the present moment, the new bone formation is evidenced, absence of clinical and radiographic signs of relapse. However, long-term follow-up is necessary to verify the absence of relapse.

Descriptors: Pathology, Oral; Bone Cysts; Oral and Maxillofacial Surgeons.

\section{Resumen}

El queratocisto comprende un quiste odontogenico que surge de los restos de la lámina dentaria asociado a alteraciones genéticas en el gen PTCH1, aumento expresión PCNA, Ki-67, extinción de varios genes supresores tumorales. Se presenta un comportamiento agresivo, invasivo, altamente redicivante y con potencial de malignización. Este relato de caso tiene como objeto presentar tratamiento conservador de un queratocisto odontogenico. El paciente femenino, leucoderma, de 19 años, encaminado al ambulatorio del servicio Cirugía y Traumatología Bucomaxilofacial, con queja de adormecimiento del labio inferior, asociado dolor en región mandibular derecha. Fue diagnosticada con queratocisto odontogenico, donde fue sometida enucleación con piezocirugía asociado a cauterización química bajo anestesia general. El tratamiento propuesto fue efectivo hasta el momento actual, la neoformación ósea es evidenciada, ausencia de signos clínicos y radiográficos de recidiva. Sin embargo, es necesario un seguimiento a largo plazo para constatar la ausencia de recidiva.

Descriptores: Patología Bucal; Quistes Óseos; Cirujanos Oromaxilofaciales.

INTRODUÇÃO

O queratocisto foi recentemente reclassificado pela OMS como cisto odontogenico, devido à falta de evidencias para sustentar classificação como tumor ${ }^{1,2}$. Compreende um cisto que surge dos restos da lâmina dentaria associado a alterações genéticas no gene PTCH1, aumento expressão PCNA, Ki-67, extinção de vários genes supressores tumorais. Apresenta comportamento agressivo, invasivo, altamente redicivante e com potencial de malignização ${ }^{1,3}$.

Os cistos ocorrem desde primeira década de vida até nona, mas são mais diagnosticados entre primeira e a quarta década ${ }^{1,3}$. São normalmente assintomáticos, mas podendo estar associado a dor, parestesia, assimetria facial, drenagem de liquido cístico, com crescimento anteroposterior, sem causar expansão óssea, sendo uma característica importante para o diagnóstico de queratocisto ${ }^{1,4,5}$. A principal região acometida é a posterior de mandíbula, podendo se apresenta como cistos solitários ou múltiplos. Em caso de múltiplas lesões, deve-se investigar outros sinais e manifestações da síndrome do carcinoma nevoide basocelular (GorlinGoltz) $)^{1,3,4,5}$
Várias modalidades de tratamento são propostas desde uma marsupialização seguindo de uma enucleação, curetagem, com a osteotomia periférica e o uso de soluções auxiliares como a solução de Carnoy ou crioterapia com intuito de remover máximo possível de remanescentes da lesão ${ }^{1,6,7}$. O cirurgião dispõe atualmente de um importante aparato, o uso de piezocirurgia que oferece mais segurança no momento da realização da enucleação e osteotomia ${ }^{9,10}$. Entretanto controle dos queratocistos de comportamento agressivo a ressecção local com margem é necessária ${ }^{1,6,7}$.

Este relato de caso tem como objetivo apresentar um tratamento conservador de um queratocisto odontogênico.

\section{CASO CLÍNICO}

Paciente sexo feminino, leucoderma, 19 anos, encaminhada ao ambulatório do serviço Cirurgia e Traumatologia Bucomaxilofacial, com queixa de dormência do lábio inferior, associado dor em região mandibular direita. Durante anamnese paciente negou doenças prévias, o exame clinico extra oral apresentava ausência de assimetria facial, e intra oral 
a ausência de mobilidade dentaria, associada a um discreto abaulamento ósseo. Ao exame tomográfico, extensa imagem hipodensa, localizadas desde a região inferior mesial ao dente 36 até o ramo ascendente da mandíbula, com limites definidos, provocando severa expansão óssea, rompimento cortical na região posterior ao dente 37 e de ramo, provocando deslocamento inferior do nervo alveolar inferior (Figuras 1 e 2).

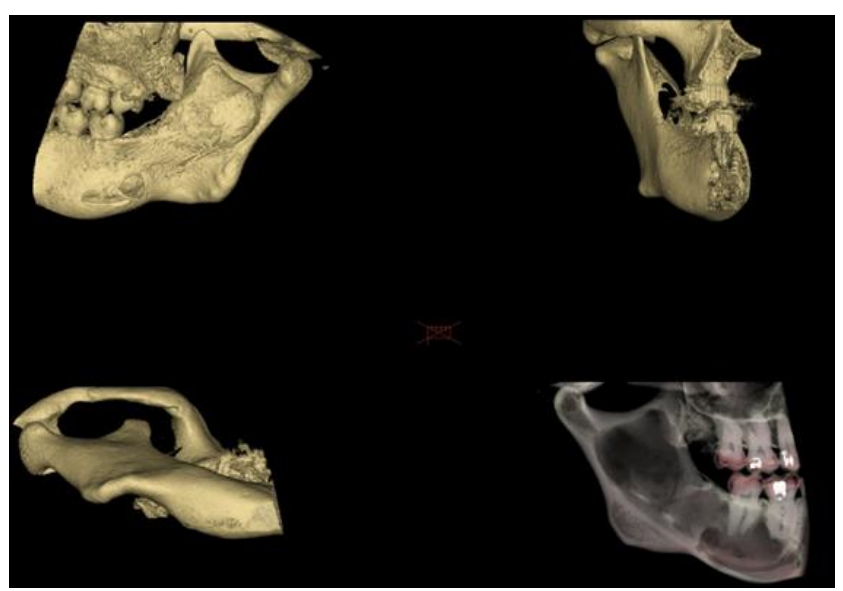

Figura 1. Tomografia tipo cone beam pré-operatória (reconstrução 3D).

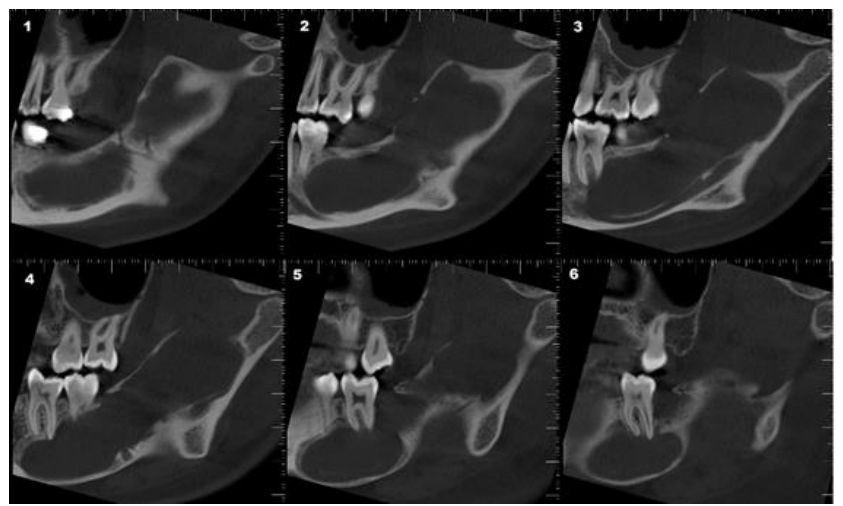

Figura 2. Tomografia tipo cone beam pré-operatória (corte sagital).

Foi realizada uma punção da lesão, onde se obteve liquido claro, seroso com material caseoso, associado biopsia incisional sob anestesia local. Ambos os materiais foram encaminhados para análise histopatológica, onde obtivemos diagnostico de queratocisto odontogênico. Após confirmação do diagnóstico foram solicitados exames laboratoriais, radiografias complementares e avaliação préoperatória de risco cirúrgico. Paciente foi submetida anestesia geral, com intubação nasotraqueal. Foi utilizado anestésico local para infiltração (mepivacaína 2\% com epinefrina 1:100.000) nas regiões onde foram planejados os acessos cirúrgicos. Realizamos incisão na região retromolar direita até primeiro pré-molar inferior ipsilateral utilizando bisturi elétrico monopolar, descolamento mucoperiosteal, e confeccionamos dois acessos para loja patológica com uma ponta OT5 por meio de piezocirurgia. Após exposição da lesão, foi iniciado a enucleação da lesão com piezosurgery (mectron ${ }^{\circledR}$ ) usando a ponteira OP3 com irrigação de água destilada, em seguida osteotomia periférica com brocas esféricas multilaminadas, associado a aplicação da solução de Carnoy, por 05 minutos, com limpeza abundante com soro fisiológico $0.9 \%$ após conclusão da cauterização química (Figuras 3 e 4). A sutura foi realizada com fio reabsorvível poliglactina 910 (Vicryl®) em ponto continuo festonado. A paciente permanece em acompanhamento clinico e radiográfico (Figuras 5,6 e 7).

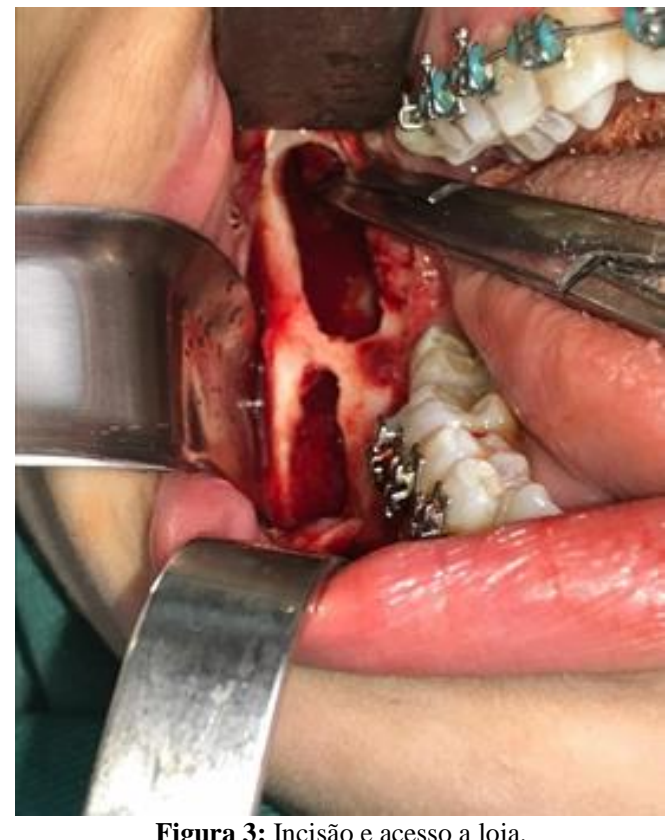

Figura 3: Incisão e acesso a loja.

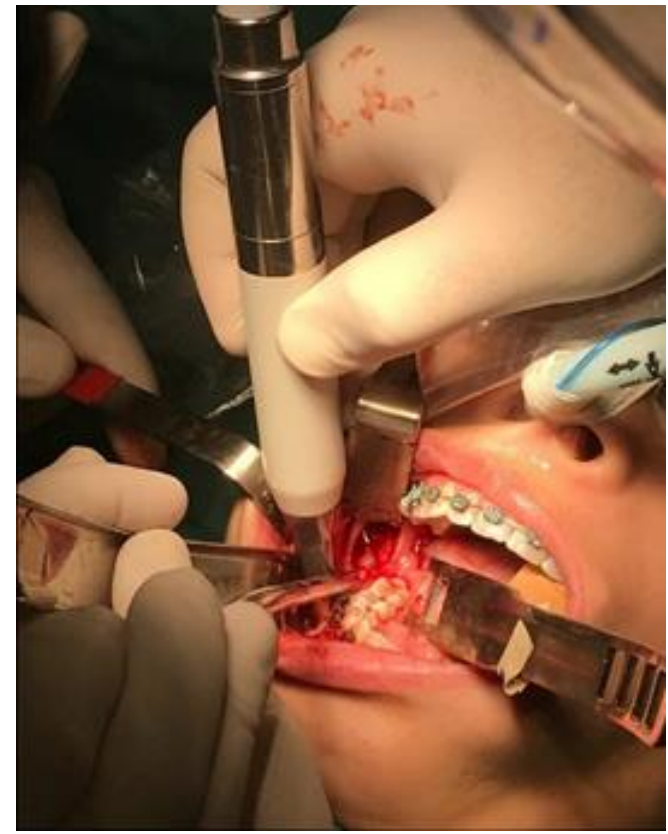

Figura 4: Enucleação com piezocirurgia.

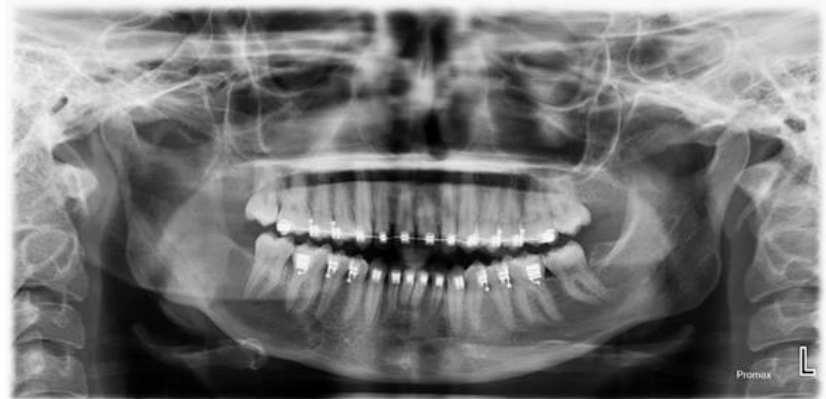

Figura 5: Radiografia panorâmica um mês após a cirurgia. 


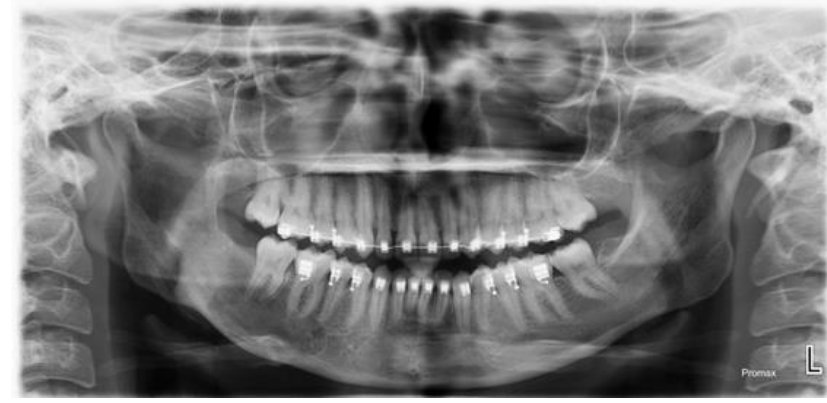

Figura 6: Radiografia panorâmica três meses após a cirurgia.

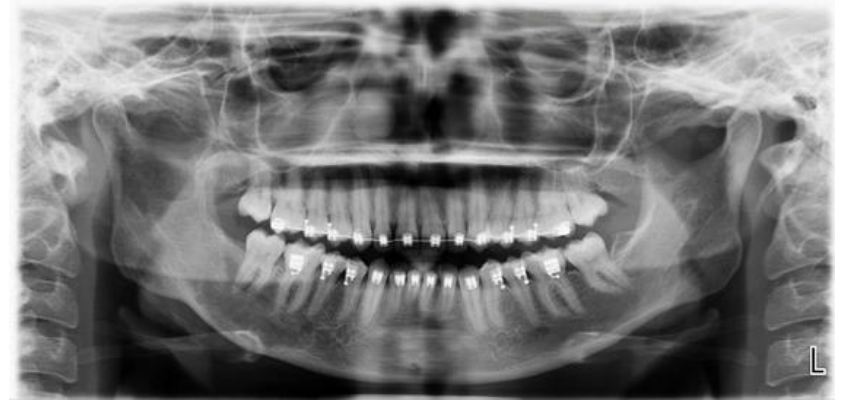

Figura 7: Radiografia panorâmica seis meses após a cirurgia.

DISCUSSÃO

Os achados radiográficos do queratocistos incluem: uma imagem radiolucida, com margens radiopacas bem limitadas, podendo estar associada dentes não erupcionados, não sendo comum reabsorções radiculares. Diagnostico diferencial desta lesão inclui cisto dentígero, ameloblastoma e cistos radiculares ${ }^{1,7}$.

A osteotomia periférica é utilizada para remover osso de até $2 \mathrm{~mm}$ de profundidade com intuito de diminuir as taxas de recidivas ${ }^{6,7}$. Outro coadjuvante é solução de Carnoy que é um agente cauterizador que causa fixação local, composto de: cloreto férrico, álcool, clorofórmio e ácido acetil glacial, sendo aplicada sobre loja óssea ou uma injeção intracistica para auxilio liberação das paredes ósseas. Tem como objetivo a destruição das propriedades osteogênicas, osteocondutoras, desvitalização e fixação das células remanescentes com intuito diminuir taxas de recorrência ${ }^{6-8}$. A solução deve ser aplicada uma única vez, durante 05 minutos, com uma penetração óssea de até $1,5 \mathrm{~mm}$, pois não existe vantagem adicional sobre exposição superior ao tempo de cinco minutos ${ }^{8,9}$. Os estudos mais atuais demonstraram que a exclusão do clorofórmio da formula, tem se mostrado benéfica pelo grande potencial carcinogênico do composto ${ }^{6}$. As complicações mais comuns do uso da solução de Carnoy são infecções, deiscência, osteomielite e neuropatias ${ }^{6,7}$.

Outro auxiliar valido é uso da crioterapia com nitrogênio líquido que tem como objetivo eliminar tecidos patológicos visíveis, destruir as células por meio de dano direito às superfícies intracelulares e extracelulares, criando cristais de gelo que alteram o equilíbrio osmótico e eletrolítico, levando à necrose pelo congelamento das células que podem levar recorrência da lesão, que pode chegar até 196 graus centígrados negativos ${ }^{6-9}$. A crioterapia apresenta uma característica vantajosa que é preservação da estrutura inorgânica óssea que favorece uma melhora no processo do reparo ósseo ${ }^{7,8}$. As reconstruções ósseas com enxerto imediato para prevenção de fraturas patológicas são possíveis ${ }^{6,7,9}$.

A piezocirurgia baseia-se em um princípio de piezoeletricidade que consiste em conversão de corrente elétrica em ultrassom, que transmite essas vibrações ao osso $^{10,11}$. Estas vibrações geram estímulos de pressão nas partículas de hidroxiapatita, que por sua vez produzem campos eletromagnéticos que deformam o tecido ósseo, cortanto-o ${ }^{9,10}$. Tem como as principais vantagens ausência de danos aos tecidos moles adjacentes, ausência de aquecimento ósseo devido não necessitar de pressão no momento da osteotomia (oferece maior conforto pósoperatório), sitio cirúrgico livre de sangue devido seu efeito de cavitação ${ }^{10,11}$.

O queratocisto pode apresentar altas taxas de recidivas de até $62 \%$, entretanto tendem apresentar bom prognostico, algumas recidivas podem demorar até 10 anos para manifestações clinicas e radiográficas $^{1,12}$. Os casos de transformação maligna são incomuns e $\operatorname{raros}^{12}$.

\section{CONCLUSÃO}

O queratocisto odontogenico compreende um cisto de comportamento agressivo, invasivo e altamente recidivante. Entretanto responde bem tratamentos mais conservadores. No caso apresentado constatamos que tratamento proposto foi efetivo até atual momento, a neoformação óssea é evidenciada, ausência de sinais clínicos e radiográficos de recidiva. Porém é necessário um acompanhamento em longo prazo para constatação da ausência de recidiva.

\section{REFERÊNCIAS}

1. Neville BW, Damm DD, Alen CM, Bouquot JE. Patologia oral e maxilofacial. Rio de Janeiro: Elsevier; 2009.

2. Stoelinga PJW. Keratocystic odontogenic tumour (KCOT) has again been renamedodontogenic keratocyst (OKC). Int J Oral Maxillofac Surg. 2019; 48(3):415-16.

3. Philipsen H.P. Tumor odontogenico queratocistico. In: Barne L, Eveson JA, Reichart P, Sindrasky D. Genetica e Patologia dos Tumores de Cabeça e Pescoço. São Paulo: Santos; 2009.

4. Marin S, Kirnbauer B, Rugani P, Mellacher A, Payer M, Jakse N. Theeffectiveness of decompression as initial treatment for jaw cysts: A 10-yearretrospective study. Med Oral Patol Oral Cir Bucal. 2019;24(1):e47-52.

5. Ali IK, Karjodkar FR, Sansare K, Salve P, Dora A, Goyal S. Nevoid Basal CellCarcinoma Syndrome - Clinical and Radiological Findings of 
Three Cases. Cureus.2016;8(8):e727.

6. Alchalabi NJ, Merza AM, Issa SA. Using Carnoy's Solution in Treatment ofKeratocystic Odontogenic Tumor. Ann Maxillofac Surg. 2017;7(1):51-6.

7. Díaz-Belenguer Á, Sánchez-Torres A, GayEscoda C. Role of Carnoy's solution in the treatment of keratocystic odontogenic tumor: a systematic review. Med Oral Patol Oral Cir Bucal. 2016;21(6):e689-95.

8. Tonietto L, Borges HOI, Martins CAM, Silva DN, Sant'Ana Filho M. Enucleation and liquid nitrogen cryotherapy in the treatment of keratocystic odontogenic tumors: a case series. J Oral Maxillofac Surg. 2011;69(6):e112-17.

9. Freitas R, Moraes PC. Cirurgia dos Cistos da região Bucomaxilofacial. In: Freitas Rd et al. Tratado de Cirurgia Bucomaxilofacial. São Paulo: Santos; 2006.

10. Consolaro MFM-O, Sant' Ana E, Moura Neto G. Cirurgia piezelétrica ou piezocirurgia em Odontologia: o sonho de todo cirurgião. Rev Dent Press Ortodon Ortop Facial . 2007;12(6):17-20.

11. Scarano A, Carinci F, Lorusso F, Festa F, Bevilacqua L, Santos de Oliveira P, Maglione M. Ultrasonic vs drill implant site preparation: postoperative pain measurement through VAS, swelling and crestal bone remodeling: a randomized clinical study. Materials (Basel). 2018;11(12):2516.

12. Medawela RMSHB, Jayasuriya NSS, Ratnayake DRDL, Attygalla AM, Siriwardena BSMS. Squamous cell carcinoma arising from a keratocystic odontogenic tumor: a case report. J Med Case Rep. 2017;11(1):335.

\section{CONFLITO DE INTERESSES}

Os autores declaram não haver conflitos de interesse.

\section{AUTOR PARA CORRESPONDENCIA}

Maylson Alves Nogueira Barros

maylson.bucomaxilofacial@gmail.com

Submetido em 20/02/2019

Aceito em 24/05/2019 